\title{
Thermal Effect on the Microwave Assisted Biodiesel Synthesis Catalyzed by Lipases
}

\author{
Ingrid C. R. Costa, ${ }^{a, b}$ Selma G. F. Leite, ${ }^{a}$ Ivana C. R. Leal, ${ }^{c}$ Leandro S. M. Miranda ${ }^{b}$ and \\ Rodrigo O. M. A. de Souza*,b \\ ${ }^{a}$ Escola de Química and ${ }^{b}$ Laboratório de Biocatálise e Síntese Orgânica, Instituto de Química, \\ Universidade Federal do Rio de Janeiro, Cidade Universitária, 21941-909 Rio de Janeiro-RJ, Brazil
}

'Faculdade de Farmácia, Universidade Federal do Rio de Janeiro, Campus Macaé, 22941-909 Rio de Janeiro-RJ, Brazil

\begin{abstract}
A reação de esterificação catalisada por lípases foi investigada através da utilização de irradiação de microondas e aquecimento convencional com a finalidade de avaliar a presença de efeitos não térmicos de microondas na síntese de biodisel. Todas as reações foram conduzidas em equipamentos dedicados a síntese orgânica como Monowave 300 e CEM Discover, a $40{ }^{\circ} \mathrm{C}$ e com controle interno da temperatura reacional através do uso de sondas de fibra ótica. Os experimentos sob aquecimento convencional foram realizados em reator automatizado EasyMax ${ }^{\mathrm{TM}}$ (MettlerToledo) que também permite o controle da temperatura interna do meio reacional. Os resultados obtidos mostram que não há diferença entre a reação conduzida sob irradiação de microondas e aquecimento convencional, diferentemente do apontado em alguns relatos da literatura.
\end{abstract}

The esterification reaction mediated by lipases was investigated applying both microwave irradiation and conventional heating in order to evaluate the existence of nonthermal microwave effects on the biodiesel synthesis. All transformations were conducted at $40{ }^{\circ} \mathrm{C}$ in both Monowave 300 and CEM Discover instruments that allowed accurate internal reaction temperature measurements with use of fiber-optic probes. The conventional heating experiment was performed in an EasyMax ${ }^{\mathrm{TM}}$ reactor (Mettler-Toledo), which also allowed accurate measurement of the internal temperature. The results revealed no difference on the reaction time or yield, differently than indicated by some results in the literature.

Keywords: microwave irradiation, lipases, thermal effect, ethyl oleate, nonthermal effects

\section{Introduction}

Biodiesel is a fuel comprised of alkyl esters of long chain fatty acids and is an alternative to petroleum diesel for reducing emissions of gaseous pollutants such as $\mathrm{CO}, \mathrm{SO}_{\mathrm{x}}$, particulate matter and organic compounds. ${ }^{1-3}$ The properties of this biofuel from renewable resources are similar to petroleum-based diesel, allowing its use either as a substitute for diesel fuel or more commonly as fuel blends. ${ }^{4,5}$ Several strategies for the production of biodiesel can be found in the literature. However, the transesterification of triacylglycerides and the esterification of free fatty acids (FFA) with low molecular weight alcohols are the most important approaches. ${ }^{2,6-8}$

Among the many enzyme classes used as biocatalysts for synthetic organic transformations, lipases (triacylglycerol

\footnotetext{
*e-mail: souzarod21@gmail.com
}

hydrolases EC 3.1.1.3) are amongst the most useful enzymes. This is because they can be applied in both aqueous and nonaqueous media, have wide substrate specificity and an excellent ability to recognize chirality and do not require labile cofactors. ${ }^{9}$ The use of enzymes for the transesterification of oils eliminates the inherent problems associated with the use of chemical catalysts. The recyclability of the immobilized enzyme and its stability are the key steps for a successful improvement of the enzymatic biodiesel process.

During the past two decades, the use of microwave dielectric heating in the field of synthetic organic chemistry has become a powerful method to enhance chemical processes and to provide (in many cases) improved yields and cleaner reaction profiles in significantly shorter reaction times. ${ }^{10}$

With respect to the use of microwave irradiation in biocatalyzed reactions, different groups have observed different results when different enzyme sources were used. Recently, Deiters and co-workers ${ }^{11}$ presented evidence 
that microwave irradiation can induce changes in the tertiary structure/conformation of a hyperthermophilic enzyme, which resulted in high biocatalytic hydrolysis rates. The lipase catalyzed reactions were also investigated for a microwave effect by us and independently by Leadbeater et al. ${ }^{13}$ group. However, no improvement on rate or selectivity under controlled experimental conditions was observed. ${ }^{12,13}$ However, this effect seems to be case sensitive since some groups still claim for a specific microwave effect on lipase catalyzed reactions. ${ }^{14-16}$

\section{Experimental}

\section{General}

All reagents and immobilized enzymes, such as Novozym 435 (Candida antarcica lipase immobilized on macroporous polyacrylic resin), Lipozyme RM IM (commercial lipase preparation of Rhizomucor miehei, immobilized in an anion-exchange resin), Lipozyme TL IM (Thermomyces lanuginosus lipase immobilized on silica) and PS Amano IM (Burkholderia cepacia lipase immobilized on diatomaceous earth) were purchased from Sigma-Aldrich and used without further purification.

\section{Esterification activity assay}

The esterification of butyric acid and butanol was used as a model reaction, similar to procedure described by Kiran et al. ${ }^{17}$ The reaction experiments were carried out at $50^{\circ} \mathrm{C}$ on a shaking incubator at $200 \mathrm{rpm}$. The reacting mixture contained $0.16 \mathrm{~mol} \mathrm{~L}^{-1}$ of butyric acid and $0.33 \mathrm{~mol} \mathrm{~L}^{-1}$ of butanol on heptane and $10 \mathrm{mg}$ de lipase. Aliquots were withdrawn from reaction mixture at appropriate time intervals (after adding $1 \mathrm{~mL}$ de methanol) and titrated with $0.02 \mathrm{~mol} \mathrm{~L}^{-1} \mathrm{NaOH}$, using phenolphthalein as indicator. One unit esterification activity is defined as $1 \mu$ mol butyric acid consumed in the esterification reaction per min per $\mathrm{mg}$ lipase.

\section{Protein assay}

Protein concentration was determined by Bradford's method..$^{18}$ The protein concentration was spectrophotometrically determined at a wavelength of $595 \mathrm{~nm}$ using the calibration curve of bovine serum albumin.

\section{Desorption assay for Novozym 435}

Proteins were removed from the support from Novozym 435 following the procedure described by
Cabrera et al. ${ }^{19}$ The amount of $1 \mathrm{~g}$ of Novozym 435 was added to $50 \mathrm{~mL}$ of $25 \mathrm{mmol} \mathrm{L}^{-1}$ phosphate $\mathrm{pH} 7$ containing $2 \%(\mathrm{v} / \mathrm{v})$ Triton X-100 and incubated for $4 \mathrm{~h}$. Under these conditions, $100 \%$ of Candida antartica lipase B (CAL-B) was desorbed from the support, checked by the activity and protein assays. The suspension was vacuum dried-filtrated and the support was washed with $2 \%$ Triton X-100 $(5 \times 50 \mathrm{~mL})$ and, finally, with distilled water $(10 \times 200 \mathrm{~mL})$.

\section{Residual activity}

At the end of the reactions, the enzyme was filtered through a filter paper and washed three times with cyclohexane. The enzyme was dried at room temperature for $24 \mathrm{~h}$. The residual activity was determined by the lipase activity assay described previously.

\section{Analytical method}

All samples were analyzed using gas chromatography-mass (GC-MS). The used Shimadzu GC-MS is equipped with a RTX-5MS column $(30 \mathrm{~m} \times 0.25 \mathrm{~mm} \times 0.25 \mathrm{~m})$, mass detector in mode electron ionization (EI) standard $(70 \mathrm{eV})$, with $\mathrm{He}$ like carrier gas. The injector was set at $260{ }^{\circ} \mathrm{C}$, the column temperature was programmed to stay at $80^{\circ} \mathrm{C}$ for $1 \mathrm{~min}$ and rise from 80 to $270{ }^{\circ} \mathrm{C}$ at $10{ }^{\circ} \mathrm{C} \mathrm{min}^{-1}$.

\section{Microwave irradiation experiments}

In this study, a standard of $10 \mathrm{~mL}$ borosilicate vessel was used in the reaction between oleic acid and ethanol under enzymatic catalysis and submitted to microwave (MW) irradiation (Monowave 300 or CEM Discover) reactor and the temperature was measured by the infrared sensor (IR) and/or the fiber optics (FO) probe, always under stirring (Monowave $300=600 \mathrm{rpm}$ and CEM Discover $=$ high). The applied microwave power was in a temperature controlled mode by the fiber optic probe. The applied power was in an "as fast as possible" mode offered by the software of Monowave 300 .

\section{Conventional heating experiments}

The conventional heating experiments were performed at EasyMax ${ }^{\mathrm{TM}}$ reactor with internal measurement of reaction temperature. For these experiments, all reagents were added to the reactor except for the enzyme which was added after stabilizing the temperature of the reaction at $40{ }^{\circ} \mathrm{C}$. The stirring speed is controlled by external software and was set to $600 \mathrm{rpm}$ to be compared to the microwave heating experiment. 


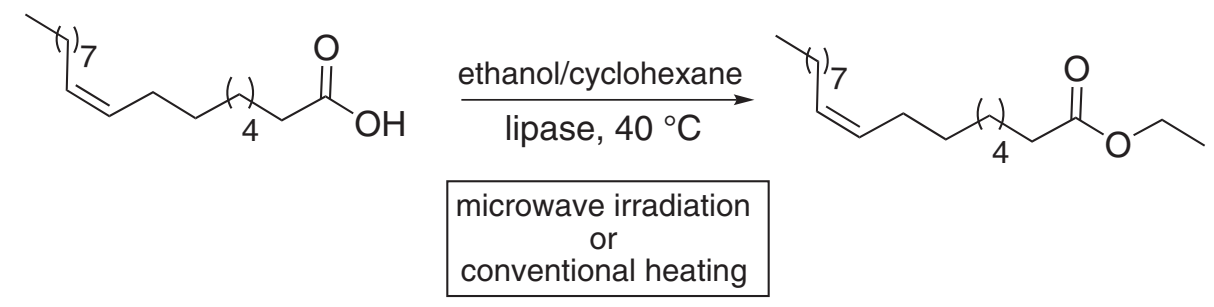

Scheme 1. Esterification reaction of oleic acid catalyzed by lipase.

\section{Results and Discussion}

In this study, it was performed a critical comparison between microwave assisted and conventional heating protocols in order to evaluate the existence of nonthermal or thermal effects in reactions catalyzed by lipases as exemplified by the formation of ethyl oleate (Scheme 1). Several immobilized enzymes were used: Novozym 435 (Candida antartica lipase B, CAL-B, immobilized on a macroporous polyacrylate resin), PS Amano IM (Burkholderia cepacia lipase immobilized on diatomaceous earth), Lipozyme RM IM (Rhizomucor miehei lipase, immobilized in an anion-exchange resin) and Lipozyme TL IM (Thermomyces lanuginosus lipase, immobilized on silica). All of the above immobilized lipase preparations can be considered as thermostable, having their optimum range of activity between 55 and $80{ }^{\circ} \mathrm{C}$, and therefore appear well suited for the planned microwave irradiation studies. ${ }^{20}$

The study began with the oleic acid esterification reactions catalyzed by Novozym 435 . Initially, the reaction of ethanol (1 equiv.), in cyclohexane as solvent $(5 \mathrm{~mL})$, was evaluated for the formation of ethyl oleate under Novozym $435(10 \% \mathrm{~m} / \mathrm{m})$ catalysis, during $60 \mathrm{~min}$ at different temperatures under microwave irradiation in "temperature control" mode. By this mode, the desired reaction temperature is achieved by coupling the feedback from a temperature probe to the modulation of magnetron output power. As shown in Figure 1, the reaction temperature has considerable influence on the lipase catalyzed formation of ethyl oleate. Similar results can be obtained in shorter reaction times by changing the temperature from 40 to $60{ }^{\circ} \mathrm{C}$.

Samples were taken at 5, 15, 30, 45 and 60 min to follow the conversion of oleic acid into ethyl oleate. Although reactions at higher temperature lead to higher conversions in shorter reaction times, in this work it was decided to continue with the reaction at $40{ }^{\circ} \mathrm{C}$. The reason is that at this temperature it is possible to have a more accurate evaluation of nonthermal microwave effects.

The next step was to investigate the oleic acid esterification reactions under different heating protocols and in different reaction vessels. Again, samples were taken at

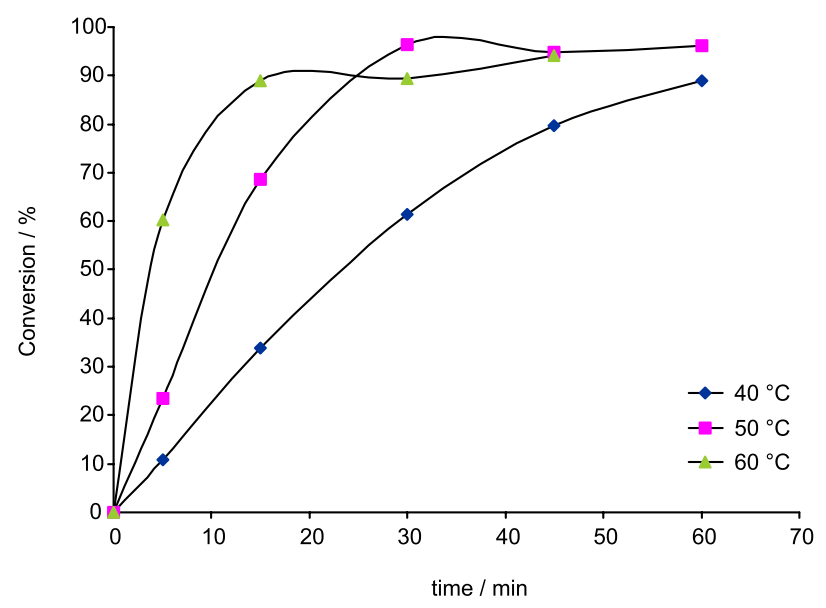

Figure 1. The influence of temperature on the conversion of oleic acid into ethyl oleate.

regular intervals in order to follow the reaction conversion (Figure 2a-c). These reactions were performed in Pyrex and quartz reactors using the CEM Discover operating again in "temperature control" mode. The conventional heating experiments were conducted with the same reactors immersed in a silicon oil bath. As shown in Figure 2a-c, after $60 \mathrm{~min}$ of reaction, the same results can be achieved either in Pyrex or quartz vessels using different heating protocols: oil bath (Figure 2a), microwave irradiation under "temperature control" mode (Figure $2 \mathrm{~b}$ ) and microwave irradiation with simultaneous cooling (Figure 2c).

Based upon the initial experiments with Novozym, in which high yields and clean reactions were observed, other enzymes were used for this transformation and the results are presented in Table 1. These reactions were carried out under microwave irradiation with CEM Discover (stirring speed at high level) and IR sensor to monitor the reaction temperature.

The results presented in Table 1 reveal that the best result for the conversion of oleic acid into ethyl oleate was the reaction catalyzed by Novozym 435. Lipozyme RM IM and PS Amano IM also show good conversions to ethyl oleate, while Lipozyme TL IM gave only $23 \%$ of conversion.

As Novozym 435 shows the best results when compared with other enzymes sources, a blank experiment was 
performed in order to confirm the role of the enzyme in this reation. This is since Novozym 435 is immobilized
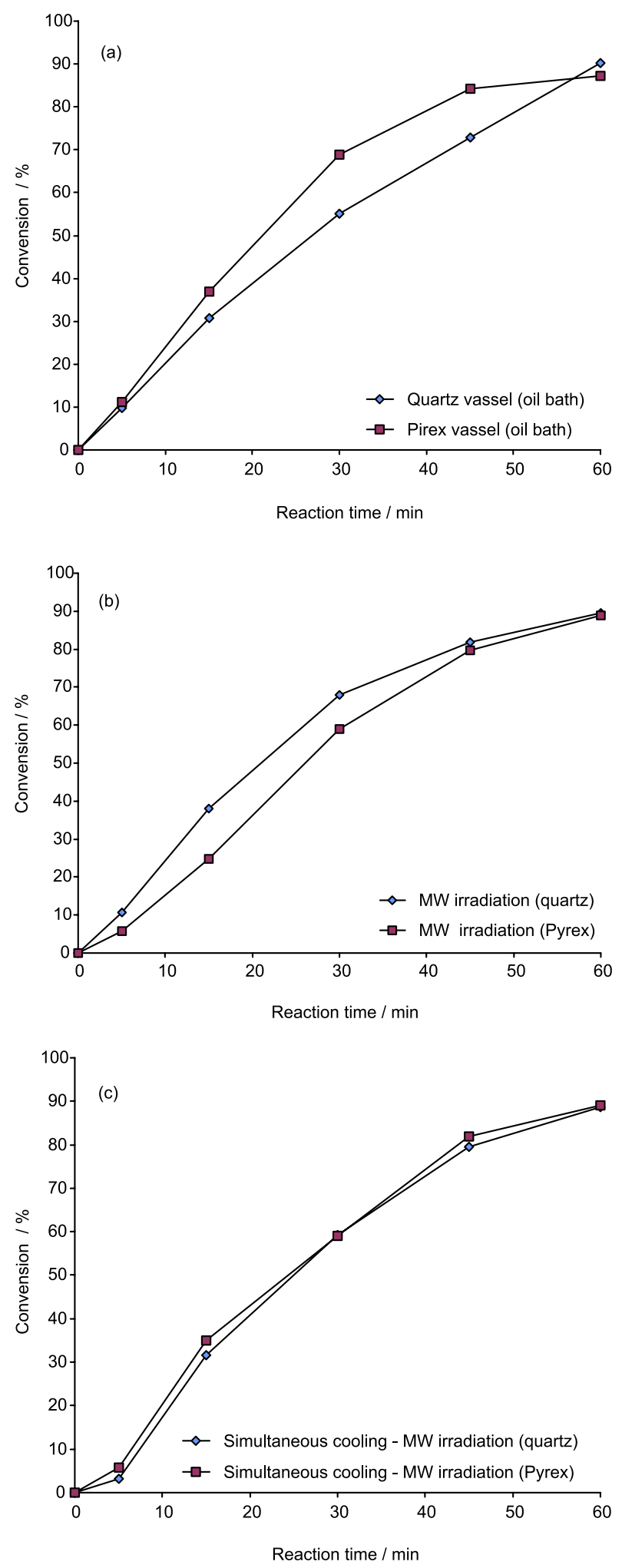

Figure 2. Results obtained in the esterification reaction under different heating protocols: (a) conventional heating and oil bath, (b) microwave irradiation and temperature control mode and (c) microwave irradiation and simultaneous cooling.
Table 1. Lipase screening on the conversion of oleic acid into ethyl oleate

\begin{tabular}{lcc}
\hline entry & Enzyme & Conversion / \% ${ }^{\mathrm{a}}$ \\
\hline 1 & Novozym 435 & 89 \\
2 & Lipozyme RM IM & 79 \\
3 & Lipozyme TL IM & 23 \\
4 & PS Amano IM & 62 \\
\hline
\end{tabular}

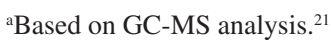

on a ionic resin and this support is, theoretically, capable of catalyzing the esterification. The enzyme was then dessorbed from the support ${ }^{19}$ and the resin (free of protein) was subjected to the same reaction conditions as used in the enzymatic reactions. The results show a conversion of only $20 \%$ after $60 \mathrm{~min}$, confirming the role of the enzyme in catalysing the reation under investigation.

Following these experiments, the effect of the catalyst loading on the conversion of oleic acid into ethyl oleate using the immobilized Novozym 435 under microwave irradiation was investigated. The same reaction profile was used with different amounts of catalysts: 1, 5, 10 and $15 \% \mathrm{~m} / \mathrm{m}$. The results are summarized in Figure 3, where it is possible to note that the reaction efficiency is dependent upon the catalyst loading. The difference in the conversion at higher catalyst loadings is less pronounced than with lower catalyst loadings. Therefore, our studies continued with $10 \% \mathrm{~m} / \mathrm{m}$ of immobilized enzyme.

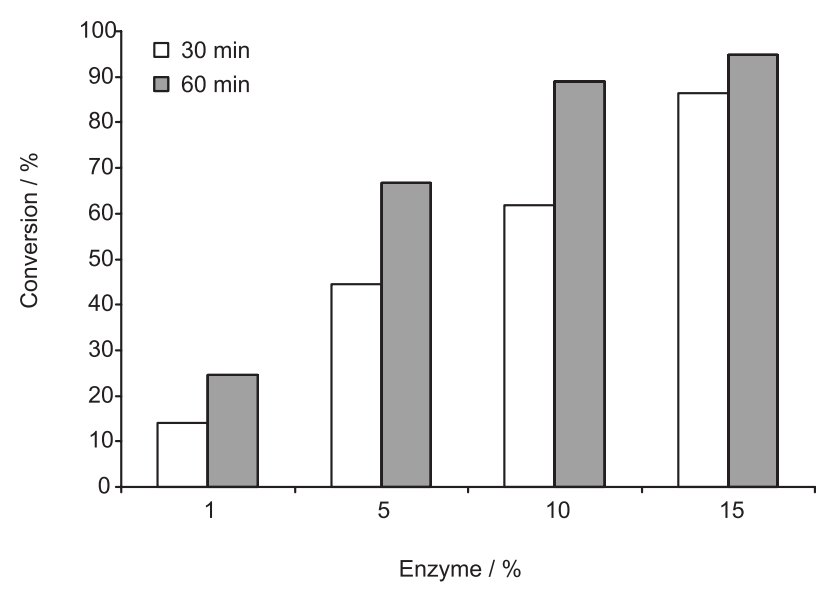

Figure 3. Effect of catalyst loading on the conversion of oleic acid into ethyl oleate.

As the esterification reaction was performed in a poor microwave absorbing solvent, the reproducibility of the experiment depends upon the used system for monitoring the temperature of the reaction. Evidence for this comes from the fact that the infrared sensor measures the temperature of the reaction vessel and, a temperature gradient between the glass wall and the reaction media for 
Table 2. Influence of temperature measurement method on the reaction yield

\begin{tabular}{lccc}
\hline entry & Microwave source & Temperature monitoring & Conversion $/ \%$ a \\
\hline 1 & Monowave 300 & FO & 79 \\
2 & Monowave 300 & IR & 86 \\
3 & CEM Discover & IR & 89 \\
\hline
\end{tabular}

${ }^{a}$ Based on GC-MS analysis. ${ }^{21}$

Table 3. Comparison between microwave irradiation and conventional heating

\begin{tabular}{lccc}
\hline entry & Heating source & Temperature monitoring & ${\text { Yield } / \%^{\mathrm{a}}}$ \\
\hline 1 & Monowave 300 & IR and FO & 80 \\
3 & EasyMax $^{\mathrm{TM}}$ - conventional heating & thermostat system & 80 \\
\hline
\end{tabular}

asolated yield.

low absorbing solvents exists. ${ }^{12}$ To check if the protocol developed is reproducible, the enzyme catalyzed reaction was performed in a Monowave 300 (stirring speed at $600 \mathrm{rpm}$ ) from Anton-Paar which simultaneously operates with both IR and fiber optic.

Table 2 presents the results for the esterification reaction with the temperature being controlled by the feedback from the fiber optic probe (entry 1), which measured the temperature inside the reaction flask, heating controlled by an infrared sensor (entry 2) and by an infrared sensor using the CEM discover reactor (entry 3 ). No difference is observed between the two experiments using temperature control by feedback from the infrared sensor. This allows for complete reproducibility of the microwave experiment. On the other hand, the conversion observed for the fiber optics temperature controlled experiment is lower.

Samples were also taken at 5, 15, 30, 45 and $60 \mathrm{~min}$ to follow the conversion of oleic acid into ethyl oleate (Figure 4). The reasons for the difference in conversion between the FO and IR temperature controlled experiments are not clear at the moment, as no temperature gradient was observed after comparing the temperature by FO and by IR using the Monowave 300 reactor. However, it is clear that difficulties in reproducibility can be encountered in microwave assisted reactions depending on the used system for temperature monitoring.

The enzyme recyclability under microwave irradiation conditions was also investigated and after 4 cycles, no difference on the reaction yield was observed. From the fourth recycle onwards, a dramatic reduction in yield is observed, ranging from 70 to $14 \%$.

In order to compare the obtained results under microwave irradiation with the results under conventional heating, this reaction was performed under controlled conditions. To achieve this objective, the EasyMax ${ }^{\mathrm{TM}}$ reactor from

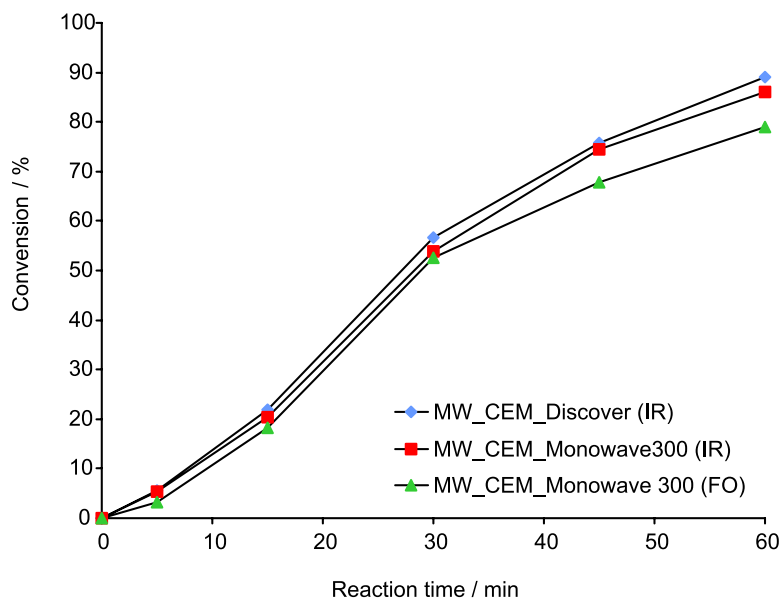

Figure 4. Conversion of oleic acid into ethyl oleate at different microwave equipments and temperature monitoring systems. Conversion based on GC-MS analysis. ${ }^{21}$

Mettler-Toledo was used, allowing to development robust processes on a laboratory scale with excellent control over the scalable parameters (internal temperature, dosing rate, heat output and safety parameters). The obtained results were compared to the reaction under microwave irradiation and the yields are reported in Table 3. This table shows that the same results are obtained under microwave irradiation and conventional heating when using controlled reaction conditions.

\section{Conclusion}

A comparison between microwave irradiation and conventional heating for the conversion of oleic acid into ethyl oleate was performed. The results show no difference upon the reaction yield when a fixed reaction time and temperature were employed despite de heat source used. On the other hand, differences were observed concerning 
the type of temperature monitoring during the microwave experiments, a fact of concern in the reproducibility of microwave experiments. A deeper analysis of this observation is under investigation and will be reported in due course.

\section{Acknowledgements}

Financial support from Conselho Nacional de Desenvolvimento Científico e Tecnológico (CNPq), Coordenação de Aperfeiçoamento de Pessoal de Nível Superior (CAPES), Fundação de Apoio a Pesquisa do Estado do Rio de Janeiro (FAPERJ) and Financiadora de Estudos e Projetos (FINEP).

\section{References}

1. Van Gerpen, J.; Shanks, B.; Pruszko, R.; Clements, D.; Knothe, G.; Biodiesel Production Technology; National Renewable Energy Laboratory (NREL): Colorado 2004.

2. Lotero, E.; Liu, Y.; Lopez, D. E.; Suwannakarn, K.; Bruce, D. A.; Goodwin Jr., J. G.; Ind. Eng. Chem. Res. 2005, 44, 5353.

3. Schumacher, L. G.; Borgelt, S. C.; Fosseen, D.; Goetz, W.; Hires, W. G.; Bioresour. Technol. 1996, 57, 31.

4. Nabi, M. N.; Akhter, M. S.; Shahadat, M. D. Z.; Bioresour. Technol. 2006, 97, 372.

5. Labeckas, G.; Slavinskas, S.; Energy Convers. Manage. 2006, 47, 1954.

6. Ma, F.; Hanna, M. A.; Bioresour. Technol. 1999, 70, 1.

7. Marchetti, J. M.; Miguel, V. U.; Errazu, A. F.; Renewable Sustainable Energy Rev. 2007, 11, 1300.

8. Santacesaria, E.; Tesser, R.; Serio, M. D.; Guida, M.; Gaetano, D.; Agreda, A. G.; Cammarota, F.; Ind. Eng. Chem. Res. 2007, 46,8355 .
9. Gotor-Fernandez, V.; Rebolledo, F.; Gotor, V. In Biocatalysis in the Pharmaceutical and Biotechnology Industry; Patel, R. N., ed.; CRC Press: Boca Raton, FL, 2007, p. 203-248; Hidalgo, A.; Bornscheuer, U. T. In Biocatalysis in the Pharmaceutical and Biotechnology Industry; Patel, R. N., ed.; CRC Press: Boca Raton, FL, 2007, p. 159-179; Ghanem, A.; Tetrahedron 2007, 63, 1721; Hasan, F.; Ali Shah, A.; Hameed, A.; Enzyme Microb. Technol. 2006, 39, 235; Ghanem, A.; Aboul-Enein, H. Y.; Chirality 2005, 17, 1.

10. Kappe, C. O.; Dallinger, D.; Mol. Diversity 2009, 13, 71.

11. Young, D. D.; Nichols, J.; Kelly, R. M.; Deiters, A.; J. Am. Chem. Soc. 2008, 130, 10048.

12. De Souza, R. O. M. A.; Antunes, O. A. C.; Kroutil, W.; Kappe, C. O.; J. Org. Chem. 2009, 74, 6157.

13. Leadbeater, N. E.; Stencel, L. M.; Wood, E. C.; Org. Biomol. Chem. 2007, 5, 1052.

14. Major, B.; Kelemen-Horvath, I.; Csanadi, Z.; Belafi-Bako, K.; Gubicza, L.; Green Chem. 2009, 11, 614.

15. Yadav, G. D.; Borkar, I. V.; Ind. Eng. Chem. Res. 2009, 48, 7915.

16. Yu, D. H.; Tian, L.; Ma, D. X.; Wu, H.; Wang, Z.; Wang, L.; Fang, X. X.; Green Chem. 2010, 12, 844.

17. Kiran, K. R.; Krishna, S. H.; Babu, C. V.; Karanth, N. G.; Divakar, S.; Biotechnol. Lett. 2000, 22, 1511.

18. Bradford, M. M.; Anal. Biochem. 1976, 72, 248.

19. Cabrera, Z.; Lorente, G. F.; Lafuentes, R. F.; Palomo, J. M.; Guisan, J. M.; J. Mol. Cat. B: Enzym. 2009, 57, 171.

20. http://www.brenda-enzymes.info accessed in January 2011.

21. EN 14105: Fat and Oil Derivatives-Fatty Acid Methyl Esteres(FAME) - Determination of Free and Total Glycerol and Mono, Di, Triglyceride Contents, Reference method No. 28, European Committee for Standardization, Brussels, 2001.

Submitted: April 30, 2011

Published online: August 30, 2011 